\title{
DA CIDADE À REPÚBLICA DAS LETRAS. JESUÍTAS, ADMINISTRAÇÃO VICE-REAL, GRUPOS LETRADOS (MÉXICO, SÉCS. XVI-XVII)
}

ANDERSON ROBERTI DOS REIS

Universidade Federal de Mato Grosso (UFMT)

\section{RESUMO}

O presente artigo propõe uma reflexão sobre o papel desempenhado pelos jesuítas na formação de grupos letrados e, pois, de parcela das elites coloniais na capital da Nova Espanha. Parte-se de uma leitura clássica a respeito desse tema, aquela oferecida pelo crítico uruguaio Ángel Rama em La ciudad letrada, a fim de buscar outras possibilidades de compreensão para as relações entre os padres da Companhia de Jesus, os grupos letrados e a administração vice-real. $\mathrm{O}$ argumento central deste artigo sustenta que a conformação política da Monarquia Espanhola e de seus vice-reinos americanos nos séculos XVI e XVII, distante da noção de Estado Moderno e mais próxima de um modelo corporativo, torna difícil o enquadramento da atividade dos padres na perspectiva de "intelectuais a serviço da monarquia absoluta".

PALAVRAS-CHAVE: Governo vice-real; Jesuítas; Grupos Letrados; Cidade das Letras; Nova Espanha.

\section{ABSTRACT}

In this article we propose a reflection on the role played by the Jesuits in training literate groups and therefore a portion of colonial elites in the capital of New Spain. We start with the Ángel Rama's classical reading on this subject in his book La ciudad letrada, in order to seek other possibilities for understanding the relationships between the Society of Jesus, the literate groups and the viceregal government. The main argument in this paper contends that the political configuration of the Spanish monarchy and its American dominions throughout the sixteenth and seventeenth centuries, closer to a corporate model than a notion of modern state, makes it difficult to frame the Jesuit's activities in a perspective of "intellectuals at the service of absolute monarchy".

KEYWORDS: Viceregal government; Jesuits; Literate Groups; Lettered City; New Spain. 


\section{Introdução (apresentando o problema)}

Em 1614, a notícia da circulação de um panfleto na Cracóvia, cidade ao sul da atual Polônia, preocupou a cúpula da Companhia de Jesus. Havia dois anos que se escutavam rumores nos salões eclesiásticos e cortesãos do leste europeu e de Roma sobre o manuscrito que revelaria um segredo guardado cuidadosamente pelos jesuítas: a primazia do desejo de riqueza e poder em seu projeto "missionário". Tratava-se da Monita privata Societatis Iesu, também conhecida como Monita Secreta, um manual supostamente concebido pela cúpula da Ordem para um número restrito de padres com instruções e estratégias para alcançar privilégios, poder e riquezas, sem contudo borrar a boa fama jesuítica ou supor ações pouco virtuosas. A publicação daquele texto atingiu em cheio as pretensões que tinha o Padre-geral Cláudio Aquaviva de encerrar tranquilamente seu generalato (iniciado em 1581) e consolidar a imagem da Companhia de Jesus como uma ordem religiosa íntegra e uniforme, apesar de apinhada de irmãos que se distribuíam pelos quatro continentes. Porém, coube a seu assistente e sucessor no generalato, Pe. Mucio Vitelleschi (que liderou Ordem entre 1615 e 1645), organizar a defesa e o contra-ataque a partir de 1615 e mobilizar o clero em favor da causa jesuítica a fim de evidenciar a fraude de que era fruto o panfleto. Iniciava-se uma disputa em torno de algo bastante precioso: a fama da Companhia de Jesus ${ }^{1}$.

Investigações, acusações, sessões do Tribunal da Inquisição, interrogatórios e refutações por escrito. Durante os anos seguintes, os superiores jesuítas recorreram a todos os meios possíveis para descobrir, deslegitimar e condenar o autor do panfleto. No curso desse processo sustentouse, pelo menos desde 1616, que Hieronim Zahorowski, um padre expulso da Companhia anos antes de o panfleto ser publicado, tinha sido o autor daquele "protocolo de comportamento" ${ }^{2}$ falsamente atribuído ao geral Aquaviva, embora o acusado nunca tenha sido condenado por isso. As respostas jesuíticas foram rápidas, mas o texto difamatório não demorou a se espalhar (ou ser espalhado) pela Europa e a encontrar leitores simpáticos à sua "causa", encorpando ao longo dos séculos XVII, XVIII e XIX a tradição antijesuítica nas disputas em torno da memória da Ordem ${ }^{3}$. O panfleto anônimo, mas creditado a um religioso

\footnotetext{
${ }^{1}$ Para referências gerais e análises desse caso, ver: SAVONE, Sabine. Between History and Myth: The Monita secreta Societatis Jesu. In: O'MALLEY, John et al. (eds.). The Jesuites II: Cultures, Sciences, and the Arts, 1540-1773. Toronto: University of Toronto Press Inc., 2006, pp. 50-65; FRANCO, José Eduardo; VOGEL, Cristine. As Monita Secreta. História de um best-seller antijesuítico. PerCursos, Florianópolis, v. 4, n. 1, pp. 93-133, 2003; ASSUNÇÃO, Paulo de. Negócios jesuíticos. o cotidiano da administração dos bens divinos. 1a. reimp. São Paulo: Edusp, 2009, pp. 50-53. Em relação ao texto propriamente dito da Monita Secreta, há várias edições em diferentes línguas, algumas disponíveis na internet. Caso se queira consultar, pode-se acessar a edição espanhola de em: http://www.banrepcultural.org/sites/default/files/brblaa738378 0.pdf. Acesso em: 12 mar. 2014.

${ }^{2}$ SAVONE, Sabine. Between History and Myth, p. 50.

${ }^{3}$ Para uma reflexão sobre as abordagens históricas da Companhia de Jesus e a discussão em torno do par "jesuitismo e antijesuitismo", ver: FABRE, Pierre-Antoine; ROMANO, Antonella. Les jésuites dans le monde moderne: nouvelles approches. Revue de Synthèse, t. 120, n. 2-3, pp.
} 
que conhecia e frequentara as fileiras da Companhia, contribuiu particularmente para reforçar uma imagem cuja fortuna se mostrou vigorosa nos últimos quatro séculos: os jesuítas sempre se organizaram estrategicamente para estar e permanecer próximos do poder.

Eis uma imagem conhecida pelos historiadores do período moderno. Muitos processos históricos poderiam evidenciar tal vizinhança com os centros de poder eclesiástico e civil pelo menos até o século XVIII: a justaposição dos jesuítas e das reformas católicas no século XVI; o voto de obediência ao papa; o desempenho da função de confessores de príncipes e reis em várias monarquias europeias; a expansão missionária mundial; a dedicação às tarefas educativas nas cidades; a presença marcante nos debates filosóficos e teológicos nos púlpitos acadêmicos e nas obras impressas etc. ${ }^{4}$. Considerados em conjunto, esses elementos conduzem o observador a uma certeza: a Companhia de Jesus não tinha sido fundada para se limitar ao claustro. A devoção contemplativa cedia lugar, nessa perspectiva, à postura ativa, segundo se nota no tom que atravessa as normas fundadoras da Ordem ${ }^{5}$.

Tal percepção da gênese e história dos inacianos na Europa moderna, e de sua proximidade com (ou, segundo seus detratores, gana por) os centros de poder, fundamentou quase sempre as interpretações sobre as missões jesuíticas mundo afora, e especificamente nas Américas. No cerne dessa afirmação, que será desdobrada mais adiante, encontra-se o problema central deste artigo: a relação entre os padres das missões americanas e o "poder político". Pretendese, precisamente com base nesse problema geral, refletir a respeito dos modos pelos quais os jesuítas participaram, em amplo sentido, do governo vice-real no México entre os séculos XVI e XVII. Tomaremos como base desta análise a interpretação proposta pelo texto, já clássico, do ensaísta uruguaio Ángel Rama, A cidade das letras (publicado postumamente em 1984 em espanhol, e em 1985, em português), segundo a qual os jesuítas integraram o grupo social responsável por, entre outras coisas, levar adiante o sistema ordenado da monarquia absoluta, facilitar a hierarquização e concentração do poder e cumprir a missão

247-260, 1999. Um apanhado sobre o "mito jesuítico" e os debates acerca da "legenda negra jesuítica" pode ser lido em LEROY, Michel. Mythe, religion et politique: la 'Légende Noire' des Jésuites. Lusitania Sacra, t. XII, 2a. série, pp. 367-376, 2000.

${ }^{4}$ Para tal proximidade durante a época dos fundadores da Ordem, vale a referência a O'MALLEY, John. Os primeiros jesuítas. Bauru: Edusc, 2004. A respeito dessas relações no âmbito hispânico, cf. ARANDIA, María Amparo L. El confesionario regio en la Monarquía Hispánica del siglo XVII. Obradoiro de Historia Moderna, n. 19, pp. 249-278, 2010; BURRIEZA SÁNCHEZ, Javier. La Compañía de Jesús y la Defensa de la Monarquía Hispánica. Hispania Sacra, n. 121, pp. 181-229, 2008; CARVAJAL ARAVENA, Patricio H. La doctrina católico-española del siglo XVII sobre el Estado. Monarquía, Estado e Imperio. Revista de Estudios Histórico-jurídicos, Valparaíso (Chile), pp. 371-397, 2009; LOZANO, Julián J. La Compañía de Jesús y el poder en la España de los Austrias. Madrid: Cátedra, 2005, Introducción.

${ }^{5}$ COMPANHIA DE JESUS. Constituições da Companhia de Jesus e normas complementares. São Paulo: Edições Loyola, 2004. 
civilizadora ${ }^{6}$. Com base nos argumentos de Rama, discutiremos a posição do autor, bem como outras explicações que the tomaram emprestado o modelo analítico, a fim de compreender sua interpretação e apresentar uma leitura distinta acerca das relações entre a Companhia de Jesus e o sistema político espanhol na capital da Nova Espanha.

Com tal objetivo no horizonte, organizamos este texto em outras três partes. Na primeira, lançaremos luz sobre os principais pressupostos de Ángel Rama. Em seguida, poremos os jesuítas em foco à medida que apresentamos o livro que, a nosso ver, incorporou e desenvolveu competentemente a premissa do uruguaio num esforço de síntese a respeito das elites letradas no México colonial: La Fortaleza Docta, da historiadora Magdalena Chocano Mena ${ }^{7}$. Nesta parte, destacaremos os elementos que enquadram as atividades dos padres na "cidade letrada" e na "fortaleza douta" - as metáforas escolhidas por nossos autores-interlocutores. Por fim, esboçamos alguns argumentos para tentar responder ao problema geral deste artigo e propor outra compreensão da relação entre jesuítas, grupos letrados e administração política na Nova Espanha.

\section{Um clássico e seus desdobramentos}

É conhecido o trecho com o qual Ángel Rama abriu o segundo ensaio da "cidade das letras":

Para levar adiante o sistema ordenado da monarquia absoluta, para facilitar a hierarquização e concentração do poder, para cumprir sua missão civilizadora, acabou sendo indispensável que as cidades, que eram a sede da delegação de poderes, dispusessem de um grupo social especializado ao qual encomendar esses encargos. Foi também indispensável que esse grupo estivesse imbuído da consciência de exercer um alto ministério que o equiparava a uma classe sacerdotal. Senão o absoluto metafísico, competia-lhe o subsidiário absoluto que ordenava o universo dos signos, a serviço da monarquia absoluta de ultramar. (...) Ambas as esferas estiveram superpostas por longo tempo, fazendo com que a equipe intelectual contasse durante séculos entre suas filas com importantes setores eclesiásticos, antes que a laicização que começa sua ação no século XVIII fosse substituindo-os por intelectuais civis, profissionais na sua maioria. Duas datas circunscrevem o período desta superposição: 1572, em que chegam os jesuítas à Nova Espanha, e 1767, quando são expulsos da América por Carlos III $^{8}$.

\footnotetext{
${ }^{6}$ RAMA, Ángel. La ciudad letrada. Montevidéu: Arca, 1998, p. 31. A edição em língua portuguesa que usaremos neste texto, lançada em 1985 com o título "A cidade das letras", é da Brasiliense.

7 CHOCANO MENA, Magdalena. La fortaleza docta. Elite letrada y dominación social en México colonial (siglos XVI-XVII). Madrid: Edicions Bellaterra, 2000.

${ }^{8}$ RAMA, Ángel. A cidade das letras. São Paulo: Brasiliense, 1985, p. 41.
} 
A longa citação é necessária, pois fornece os primeiros indícios a respeito do que é a ciudad letrada e, ao mesmo tempo, vincula os jesuítas (que viajaram ao México) àquele processo histórico. Lendo o fragmento, sabemos imediatamente que Rama apontou a necessidade de formar um grupo social, na colônia, capaz de cumprir funções referentes à continuidade do "sistema ordenado" (e aqui ele se remete à noção de "ordem" discutida no primeiro ensaio da obra) da monarquia, à concentração e hierarquização do poder e à sequência da missão civilizadora. Tratava-se de uma "equipe intelectual", à qual competia o manuseio do universo simbólico a serviço da "monarquia absoluta de ultramar", apta a sobrepor as esferas religiosas e políticas. A superposição de ambas as esferas, conforme notou o autor, foi circunscrita pelos anos de $1572 \mathrm{e}$ 1767, período de permanência da Companhia de Jesus na Nova Espanha. Logo, o grupo social, cuja necessidade Rama evidenciou, formou-se a partir da chegada dos jesuítas ao México e, podemos supor, com sua colaboração. A cidade letrada - que se segue à pólis ordenada na disposição da obra começava a ser construída. Antes de examinarmos como o autor interpretou a atuação dos jesuítas na composição da ciudad letrada, cabem algumas palavras acerca da concepção mais ampla que Ángel Rama tinha da formação urbana e cultural na América.

Da perspectiva do crítico uruguaio, devemos lembrar, as cidades na América eram os resultados materiais e inorgânicos da projeção de um "sonho de ordem", cujo primeiro exemplo pode-se avistar na Tenochtitlán remodelada após a conquista espanhola. Elas tinham, portanto, uma "dupla vida": a física (consoante às construções materiais, às ruas e aos edifícios) e a simbólica (correspondente aos signos, às palavras e à razão ordenadora), que antecedia e se sobrepunha àquela $a^{9}$. Nesse sentido, antes mesmo de qualquer construção material, havia um ordenamento na esfera dos signos, que continuaria a existir durante e depois do surgimento da parte concreta. Para retomar o mote foucaultiano utilizado por Rama, as palavras descolavam-se das coisas. Definiase assim a primazia da "cidade das letras" sobre a "cidade real", da representação simbólica sobre a edificação material. Não por acaso, segundo Rama, as instruções expedidas no gabinete real e remetidas aos primeiros conquistadores utilizavam invariavelmente o vocábulo "ordem", palavra-chave do projeto de transposição de certa "razão ordenadora", preexistente, à realidade americana ${ }^{10}$.

Essa interpretação evidencia o elemento que perpassa todos os ensaios da obra em análise: as relações entre as esferas da cultura e da política, entre a cidade letrada e a cidade material. Para o autor, no "centro de toda cidade, houve uma cidade letrada que compunha o anel protetor do poder e o executor de suas ordens [...]". Na sequência, ele nos informa quem eram os habitantes daquela cidade: "uma plêiade de religiosos, administradores, educadores,

\footnotetext{
${ }^{9}$ RAMA, Ángel. A cidade das letras, pp. 32-33.

${ }^{10}$ RAMA, Ángel. $A$ cidade das letras, pp. 26-27.
} 
profissionais, escritores e múltiplos servidores intelectuais". Estes, os homens letrados, eram os responsáveis por sustentar o poder e executar suas ordens: as letras desenhadas por suas penas associavam-se às "funções de poder", cuja origem se encontrava na corte ${ }^{11}$.

A cidade letrada configura-se, pois, numa espécie de fortaleza simbólica encravada no centro de poder, que tem por objetivo legitimar a ordem social e política vigente. Essa função é exercida por meio da inserção de letrados na administração das instituições coloniais encarregadas de ordenar e controlar a vida na América; e por meio da evangelização, da educação e das produções literárias, que disseminavam os valores europeus às populações indígenas e crioulas (nas palavras de Rama, a "ideologização de multidões"), mantendo cada um em seu devido lugar social. Nesse esquema explicativo, os esforços de evangelização, os projetos educativos, a formação da juventude "nas letras e virtudes" atendiam aos interesses do poder. A face religiosa de tais empresas era uma máscara, como o crítico uruguaio enfatizou ao relacionar a "razão ordenadora prévia" à noção de ideologia:

Ao mesmo tempo, esse projeto [racional prévio] exige, para sua concepção e execução, um ponto de máxima concentração de poder que possa pensá-lo e realizá-lo. Esse poder já é visivelmente temporal e humano, ainda que se mascare e legitime através dos absolutos celestiais. É próprio do poder necessitar de um extraordinário esforço de ideologização para se legitimar; quando se despedaçarem as máscaras religiosas, construirá opulentas ideologias substitutivas. A fonte máxima das ideologias procede do esforço de legitimação do poder ${ }^{12}$.

As aspas colocadas nos verbos evangelizar e educar, no trecho seguinte, são também eloquentes:

Ainda que isolada dentro da imensidão espacial e cultural, alheia e hostil, competia às cidades dominar e civilizar seu contorno, o que primeiro se chamou "evangelizar" e depois "educar". Apesar de que o primeiro verbo foi conjugado pelo espírito religioso e o segundo pelo leigo e agnóstico, tratava-se do mesmo esforço de transculturação a partir da lição europeia ${ }^{13}$.

Segundo Rama, evangelizar e educar tinham o mesmo sentido: um esforço de transculturação ${ }^{14}$, com base na lição europeia, por meio da superposição das esferas religiosa e política, das cidades letrada e real. Nesse prisma, as atividades originadas no núcleo urbano letrado, em especial aquelas ligadas às tarefas encabeçadas pelos setores eclesiásticos, eram consideradas

\footnotetext{
${ }^{11}$ RAMA, Ángel. $A$ cidade das letras, p. 43.

12 RAMA, Ángel. $A$ cidade das letras, p. 26.

${ }^{13}$ RAMA, Ángel. $A$ cidade das letras, pp. 37-38.

${ }_{14}$ Para a discussão sobre a apropriação do conceito de "transculturação" da obra de Fernando Ortiz por Ángel Rama, ver CUNHA, Roseli B. Transculturação narrativa: seu percurso na obra crítica de Ángel Rama. São Paulo: Humanitas, 2007, p. 109 e ss.
} 
indispensáveis ao projeto colonizador. Rama não parece conceder muita "autonomia" às empresas pastorais e educativas das ordens religiosas, cujas metas surgem sempre atreladas à noção de legitimação do poder imperial.

$O$ debate sobre a vinculação dos letrados coloniais com o poder político espanhol evidencia o pano de fundo sobre o qual o crítico uruguaio costura sua reflexão: a função social dos intelectuais. Para tanto, Rama criticou a excessiva frequência com que as análises marxistas conceberam os intelectuais como meros "executantes dos mandatos das Instituições (quando não das classes)" e aproxima-se da perspectiva aberta pelos sociólogos Karl Mannheim e Alvin Gouldner, manejando "uma relação mais fluida e complexa entre as instituições ou classes e os grupos intelectuais"15. A hipótese delineada por Rama sustenta que os letrados são ao mesmo tempo servidores e donos do poder, na medida em que podem interferir nas mensagens (normas) que devem retransmitir, sem que, com isso, abandonem a condição de "funcionários". Em vez de apenas executar as ordens de "instituições" ou "classes", os intelectuais têm a condição de modificá-las, pois são eles os responsáveis pelo exercício da "linguagem simbólica da cultura". Porém, de um modo ou de outro, conforme a interpretação de Rama, o domínio dos sistemas simbólicos sugere a legitimação do poder político, a constituição de ideologias públicas. Nesse sentido, a cultura articulada na cidade letrada - e, sublinhe-se, restrita a ela - continua a servir às pretensões políticas e materiais próprias da cidade real, reproduzindo-as ${ }^{16}$.

\footnotetext{
${ }^{15}$ RAMA, Ángel. A cidade das letras, p. 47. A explicitação da escolha pela sociologia cultural (e do conhecimento) de Mannheim nos parece particularmente interessante, pois, à semelhança do que se passou com a fortuna crítica da obra do sociólogo húngaro, pode-se objetar que a interpretação de Ángel Rama parece oscilar entre a tradição marxista que ele refuta e a perspectiva "mais fluida" atribuída a Mannheim. Ocorre que mesmo a obra desse sociólogo parecia situar-se num campo de disputa, nos anos 1920 e 1930, dentro do qual se tentava delimitar e resolver "o problema da intelligentsia socialmente desvinculada". O cerne da tese de Mannheim consistia no paulatino distanciamento das categorias de estrutura e superestrutura para afirmar a existência de um grupo social, os intelectuais, cujas ações não poderiam ser compreendidas se orientadas apenas por sua referência a uma classe social. A intelligentsia conformaria, assim, um grupo "socialmente instável", desvinculado de "pontos de vista de classe", e por isso mesmo em posição privilegiada no processo de compreensão do mundo e da proposição de ações sociais "totais". Os críticos de Mannheim, no entanto, já apontaram com alguma razão que tal pretensão "não-vinculadora" não se distanciava por completo da perspectiva marxista. Do mesmo modo, pode-se afirmar que a formulação de Rama, embora reivindicasse uma teoria mais "fluida", pressupôs os intelectuais como executores de mandatos advindos de um centro de poder. Para um apanhado da perspectiva do sociólogo húngaro acerca da intelligentsia, cf. MANNHEIM, Karl. Ideologia e Utopia. 2a. ed. Rio de Janeiro: Zahar Ed., 1972, pp. 178-196; . Sociologia da Cultura. 2a. ed. 2a. reimp. São Paulo: Perspectiva, 2008, pp. 69-139, especialmente pp. 81-82. Para uma crítica a sua obra desde a perspectiva marxista, cf. LÖWY, Michael. As aventuras de Karl Marx contra o Barão de Münchhausen. Marxismo e positivismo na sociologia do conhecimento. 6a. ed. São Paulo: Cortez, 1998, pp. 78-92.

${ }^{16}$ A relação entre a cultura e a vida material (política e econômica), sob o ponto de vista de Rama, aparece com clareza no final do primeiro ensaio: "A estrutura cultural flutuava sobre a econômica, reproduzindo-a sutilmente, daí que os espíritos mais lúcidos, os que mais frequentemente foram condenados pelo ditado constitucional que se revestia de ditado popular,
} 


\section{A formação das elites letradas: o foco nos jesuítas}

A análise de Rama sobre a função social dos intelectuais e de sua integração ou não ao "poder" aproxima-se mais de uma interpretação sociológica do que de uma história cultural ou intelectual. 0 crítico uruguaio esboça um modelo sociológico para esquadrinhar o lugar dos grupos letrados em sociedades urbanas e, portanto, compreender tanto a atuação de um escritor no início do século XVII - o citado Bernardo de Balbuena - quanto a postura de um intelectual como Justo Sierra, no XIX. É provável que esse modelo seja um valioso instrumento de análise das elites letradas em várias circunstâncias e momentos históricos, muitos deles mencionados pelo autor. Entretanto, gostaríamos de aproximá-lo de nosso objeto de estudo: a presença dos jesuítas no México.

No ensaio La ciudad letrada, o segundo da obra, Rama destacou os inacianos. Conforme o modelo proposto pelo autor, a chegada dos padres ao México, em 1572, teria sido concomitante à formação e à consolidação de uma equipe intelectual que habitava a cidade letrada, o "anel protetor do poder", demarcando o início de um período de imbricação das esferas religiosa e política que se estenderia até o século XVIII. A "façanha educativa" da Companhia de Jesus no México, para além de ser "paralela" à organização de tal equipe, era "uma pequena ainda que não desprezível parte da poderosa articulação letrada que rode[ava] o poder, manejando as linguagens simbólicas em direta subordinação das metrópoles"17. Eis a primeira representação dos jesuítas.

Para formular tal imagem, o ensaísta uruguaio valeu-se do relato produzido pelo Pe. Juan Sánchez Baquero sobre as razões da missão jesuítica no México, segundo as quais os inacianos deveriam "preencher um vazio": educar a juventude crioula, esquecida pelas demais ordens religiosas. O excerto da obra de Baquero, apropriado depois por outros cronistas e incorporado pela historiografia jesuítica, ajustou-se à hipótese de Ángel Rama, que vinculava a educação jesuítica à articulação de letrados a serviço do império. Isso explica parcialmente a predileção do ensaísta pelas incursões dos jesuítas no México, embora aqueles padres já residissem em outras cidades americanas anteriormente, inclusive no vice-reinado do Peru. Entretanto, a imagem talhada por Baquero de uma juventude ociosa, rica, desregrada e carente de educação que poderia vir a ser parte da elite dirigente - representava com clareza qual seria o papel dos jesuítas na Nova Espanha.

Mais adiante, enquanto apresenta as características da ciudad letrada e sublinha que a época barroca foi marcada por "atender à ideologização das multidões", Rama novamente lança luz sobre a Companhia. Dessa vez, o autor remete-se à militância propagandística que as equipes treinadas (entre elas, os jesuítas) cumpriam no ambiente da Contrarreforma. Resta claro que os grupos

se esforçavam para desvendá-la, indo além do centro colonizador para recuperar a fonte cultural que o abastecia obscuramente". RAMA, Ángel. A cidade das letras, p. 39.

${ }^{17}$ RAMA, Ángel. $A$ cidade das letras, p. 42. 
letrados na América também cumpriam tal "missão". Por fim, algumas linhas depois, o ensaísta lembrou que a presença dos jesuítas havia sido solicitada pelo vice-rei da Nova Espanha, Martín Enríquez, para realizar outra tarefa que fortaleceu a cidade letrada: a formação da elite dirigente que deveria administrar "a sociedade a serviço do projeto imperial, robustecendo seus laços com a Coroa e a Tiara"18.

Três imagens, pois, são cunhadas para representar o papel dos jesuítas "mexicanos" em relação à cidade das letras: partícipes da articulação entre os grupos letrados e os círculos de poder (aqui associado à administração imperial); militantes e propagandistas da Contrarreforma; e formadores das elites dirigentes coloniais. Nas três representações, a Companhia de Jesus está sempre a serviço de algo, seja dos círculos de poder, da reforma católica ou dos interesses do vice-rei/Coroa. Nesse sentido, os aspectos que poderiam escapar a esse "caráter auxiliar" são deixados de lado. A pergunta emergente é: a "façanha educativa" dos jesuítas, no México, explica-se unicamente pelo viés da ciudad letrada, pela formação de um "anel protetor do poder e executor de suas ordens", tal como propõe Rama?

Como dissemos, o modelo analítico de Ángel Rama pode ser bastante útil à compreensão da função social do intelectual na história ibero-americana, tópico que não nos interessa neste artigo. Contudo, no que se refere à participação dos jesuítas nesse processo durante os séculos XVI e XVII, acreditamos que a explicação seja insuficiente - e argumentaremos nesse sentido mais abaixo. As atividades da Companhia de Jesus reduzem-se, no esquema da ciudad letrada, a um braço da Coroa com a função de legitimar o poder político e a dominação imperial sobre o continente por meio da formação de grupos letrados. Essa interpretação, que limita os elementos religiosos a máscaras ideológicas, foi apropriada por estudos mais recentes. É o caso, por exemplo, da notável tese de doutorado, publicada em 2000 sob o título $L a$ fortaleza docta, da historiadora Magdalena Chocano Mena sobre as elites letradas e a dominação social no México colonial. A pesquisadora aprofundou o pressuposto de Rama sobre o papel dos letrados no México, que "sancionaron el orden social y aseguraron su lugar de privilegio en el mismo"19, o que se evidencia no próprio título da obra, que indica a perspectiva mais ampla de sua reflexão. A fortaleza docta pode ser outra face da ciudad letrada, pois ambas abrigaram, segundo seus arquitetos, intelectuais interessados em se fechar em círculos herméticos e legitimar a ordem social vigente na capital do vice-reino ${ }^{20}$.

\footnotetext{
${ }^{18}$ RAMA, Ángel. $A$ cidade das letras, p. 45.

${ }^{19}$ CHOCANO MENA, Magdalena. La fortaleza docta, p. 26.

20 "En el siglo XVI se plasmaron, pues, dos procesos relevantes que fijaron el ámbito de poder de la elite letrada colonial. A la vez que el acceso a la alta cultura a individuos pertenecientes a la población india mestiza quedó bloqueado, se estableció un consenso sobre el tipo de evangelización que se deseaba proyectar sobre ésta. La clase dominante definió así un territorio intelectual exclusivo que dejó en manos de su sector letrado el control de una enorme autoridad político-social, pues sólo podían ser miembros de la burocracia eclesiástica y civil aquellos que
} 
Ao passo que o caráter ensaístico da obra do uruguaio lhe permitiu certa liberdade para fazer generalizações, Chocano Mena esmerou-se para definir claramente os conceitos e objetos de sua pesquisa doutoral. Nota-se isso na maneira como a autora abordou os termos utilizados para nomear os grupos letrados e, assim, sugerir o uso de "intelectuais" no lugar de "elites letradas":

Los conocedores del latín eran no sólo los clérigos y monjes, sino los llamados, en sentido estricto, "letrados", esto es, abogados y juristas, y también los médicos educados en la universidad. Fuera de este grupo conocedor del latín, existían personas con conocimientos y capacidades intelectuales que no dominaban la lengua (o que si la conocían lo habían logrado de forma autodidacta o en circunstancias extraacadémicas), y que, por ende, no estaban comprendidas dentro de esta elite letrada. Por eso, la noción de intelectuales es bastante más amplia que la noción de elite letrada ${ }^{21}$.

Essa observação é bastante relevante por dois motivos. Em primeiro lugar, porque nos lembra que, no período colonial, o termo "letrado" associavase, quase sempre, aos magistrados, juristas e advogados, obrigando-nos a fazer ressalvas. Com efeito, ao nos referirmos aos "letrados", nos limites deste texto, estamos pensando sempre nos grupos educados, que dominavam o latim e o espanhol, tornando-se aptos a candidatarem-se a cargos na administração civil e eclesiástica, a seguirem carreira acadêmica ou religiosa ou mesmo a produzirem obras literárias. Em segundo lugar, a opção da historiadora pelo termo "intelectual", menos utilizado no México colonial, reflete o corpo teórico com o qual ela dialogou: do sociólogo Max Weber, passando por Gramsci até chegar a Pierre Bourdieu e Jacques Le Goff ${ }^{22}$. Assim como Rama, Chocano Mena preocupou-se com a "função social do intelectual" - aproximando-se bastante, também, da sociologia da cultura como saída teórica para seu problema de pesquisa.

De acordo com a perspectiva de La fortaleza docta, os jesuítas, junto com o clero secular, influenciaram a elite social por meio de suas escolas. Nesse ponto, não reside nenhuma novidade, uma vez que a historiografia vinculou com frequência as atividades pedagógicas e pastorais da Companhia a certo "elitismo"23. No México, sabemos, os jesuítas também estreitaram laços com os

tuvieran una educación superior, de la cual estaban excluidas las mujeres en su conjunto". CHOCANO MENA, Magdalena. La fortaleza docta, pp. 153-154.

${ }^{21}$ CHOCANO MENA, Magdalena. La fortaleza docta, p. 36.

${ }^{22}$ CHOCANO MENA, Magdalena. La fortaleza docta, pp. 31-33.

${ }^{23}$ Nesse caso, o termo "elitismo" indica a relação estreita existente entre os jesuítas e as elites (sociais, acadêmicas, econômicas, políticas) locais - o que, em muitos casos, resultou em alianças e cooperações entre os grupos dirigentes e os padres. Para abordagens desse aspecto da história da Companhia, ver: GONZALBO AIZPURU, Pilar. Historia de la educación en la época colonial: la educación de los criollos y la vida urbana. México: Colmex, 1990, pp. 143; 145; ALFARO, Alfonso. La educación: los nudos en la trama. In: BERMEO, José Luis (Coord.). Colegios jesuitas. Revista Libro, México DF, n. 58, 2001, p. 12; GIARD, Luce. Orígenes de la enseñanza jesuita. In: BERMEO VEGA, José Luis (Coord.). Colegios jesuitas. Revista Libro, México DF, n. 58, 
acaudalados. Porém, Chocano Mena complementou a apreciação, afirmando que os padres vocalizavam um discurso religioso "en la legitimación del orden imperial", já que para "los letrados coloniales, un orden social secular desprovisto de fundamentos religiosos era inconcebible ${ }^{\prime \prime 24}$. Era inconcebível por quê? Do ponto de vista da autora, à semelhança do que se percebe no livro de Rama, o discurso religioso era indispensável porque constituía o elemento de cunho metafísico e ideológico que deveria encobrir o projeto imperial de domínio sobre indígenas e mestiços, impedindo-os de chegar ao cume da pirâmide social. Desse modo, as instituições educativas estavam à testa do processo, pois, além de responsáveis pela formação de homens que governariam o México, criavam as condições para que os fundamentos religiosos repercutissem na sociedade por meio de festas, atos literários, disputas públicas, certames etc. ${ }^{25}$.

Magdalena Chocano Mena interpretou a educação quase sempre como o resultado de disputas entre grupos sociais - invariavelmente, entre peninsulares e crioulos, conforme se nota no capítulo 4 de seu livro. E nessa zona de embates aparece inserida a Companhia de Jesus. O corolário desse princípio é que qualquer esforço educativo no México só poderia ser resultado dessas contendas e do interesse de um dos grupos (ou da Coroa) de se sobrepor aos demais. Assim, a autora desconsiderou outros elementos que impulsionaram a criação de colégios, universidades e congregações, tais quais: a própria gênese da Companhia de Jesus, os "resquícios humanistas" mesclados à fundamentação escolástica dos padres, as circunstâncias que envolveram a instalação da Ordem no México, entre outros. Sua análise da participação das elites letradas no "aparato de dominação colonial" do vice-reino fica bastante visível na interpretação construída sobre o surgimento de tratados políticos entre os teóricos cristãos nos séculos XVI e XVII a fim de combater as teorias de Maquiavel. Segundo a autora, na Nova Espanha, "la constitución misma del orden colonial imponía un rechazo si cabe aún más rotundo para la teoría maquiavélica o de la 'razón de estado'"'26. Logo, Chocano Mena argumentou que a oposição ao modelo político d'O Príncipe entre os intelectuais católicos novohispânicos guardava relação direta com a situação colonial e notadamente com a necessidade de afirmar o domínio da monarquia. Novamente as aspas nos fornecem boas pistas a respeito do modo como a autora pensa um termo-chave à compreensão da vida política no vice-reino:

2001, p. 34; ROMANO, Antonella. Modernidade da Ratio studiorum. Plano racional dos estudos: gênese de um texto normativo e compromisso com uma prática docente. In: DUMORTIER, François-Xavier et al. Tradição jesuítica: pedagogia, espiritualidade, missão. São Paulo: Loyola, 2006, p. 57.

${ }^{24}$ CHOCANO MENA, Magdalena. La fortaleza docta, p. 40.

${ }^{25}$ Para uma análise das festas públicas no México colonial como "espaços de exceção às normas", cf. BRAVO, María Dolores. La fiesta pública: su tiempo y su espacio. In: RUBIAL GARCÍA, Antonio (coord.). La ciudad barroca. México DF: FCE, 2005, v. II, pp. 435-460.

${ }^{26}$ CHOCANO MENA, Magdalena. La fortaleza docta, p. 261. 
La figura del príncipe cristiano entrañaba una afirmación del dominio de la monarquía hispánica, pero también proporcionaba un retrato ideal de los deberes del soberano y sus representantes para con el pueblo. Los letrados coloniales adaptarían esta figura para expresar en público sus expectativas respecto al "buen gobierno" del virrey de Nueva España. Aunque los temas utilizados no se distinguen por su variedad, los mensajes que se pusieron de manifiesto ante cada uno de estos gobernantes no se limitaron a la pura actualización de un patrón establecido ${ }^{27}$.

Ora, podemos perguntar se somente os "letrados coloniais" se colocavam contra as premissas expostas por Nicolau Maquiavel em $O$ Príncipe. Não se tratava, antes, de uma postura comum à maioria dos teóricos católicos, que se viram provocados pelos desafios postos tanto pelo autor florentino como pela ruptura luterana ${ }^{28}$ ? Parece-nos que a segunda pergunta indica um caminho interpretativo mais seguro, dado que a oposição a Maquiavel não se limitou às fronteiras do império espanhol. No entanto, a leitura de Chocano Mena parece sugerir que toda a teoria política formulada por pensadores espanhóis entre os séculos XVI e XVII, na "Velha" ou na Nova Espanha, era apenas uma justificativa para o controle da América. Essa posição nos causa estranheza, já que boa parte daquelas doutrinas se relacionava a questões anteriores à colonização e que não diziam respeito unicamente à noção de domínio, tal qual esboçada pela pesquisadora.

La fortaleza docta é, sob nosso ponto de vista, o exemplo mais bemacabado de aplicação sistemática dos pressupostos da ciudad letrada à Nova Espanha - e por isso se tornou referência para os interessados no tema. Como tal, a obra partilha do pressuposto que vincula sempre o universo letrado - e suas origens, o sistema educativo - à legitimação do poder político e da ordem social vigente. No interior de uma "fortaleza" ou de uma "cidade", esses homens manejavam os signos de modo a servir ao império espanhol. Esta era sua função. De nossa parte, pensando exclusivamente nas atividades jesuíticas relacionadas a essa matéria, queremos problematizar tal leitura e sugerir outra saída: pensar a educação oferecida pela Companhia de Jesus e os letrados a ela ligados (e vinculados à administração pública do vice-reino) sob a ótica do bom governo, sem aspas, segundo a qual o sentido da formação de homens de "letras e virtudes" não se limita aos interesses da Coroa, mas se vincula à noção de bem comum - que pode ou não coincidir com os negócios da monarquia espanhola ${ }^{29}$.

\footnotetext{
${ }^{27}$ CHOCANO MENA, Magdalena. La fortaleza docta, p. 270.

${ }^{28}$ A historiadora Alicia Mayer listou e analisou a produção dos diferentes teólogos novo-hispanos que responderam ao luteranismo entre os séculos XVI e XVII, evidenciando os múltiplos matizes que perpassaram as obras daqueles homens, fossem eles dominicanos, franciscanos ou jesuítas. MAYER, Alicia. Lutero en el paraíso: la Nueva España en el espejo del reformador alemán. México DF: FCE, 2008, pp. 53-97.

${ }^{29}$ Tal relação entre jesuítas e bom governo foi evidenciada por: REIS, Anderson R. dos. $A$ Companhia de Jesus no México. Educação, bom governo e grupos letrados. 2011. 280 f. Tese
} 


\section{Os jesuítas na cidade, na fortaleza e... na república (respondendo ao problema)}

Os esquemas interpretativos da "cidade letrada" e da "fortaleza douta" sugerem, portanto, um "lugar" para os jesuítas. Valendo-se de sua empresa educativa, aqueles religiosos teriam contribuído sistematicamente para a formação, em seus colégios, dos letrados coloniais e, por consequência, para o enraizamento do poder da monarquia espanhola na América. O argumento central de Rama, por exemplo, supõe três esferas em relação: os jesuítas (e seu projeto educativo), os grupos letrados da colônia (administradores e burocratas em geral, além dos próprios religiosos) e a realização do poder ("levar adiante o sistema ordenado da monarquia absoluta"). A "façanha educativa" da Ordem no México foi paralela à (e responsável pela) estruturação administrativa e eclesiástica levada a cabo por uma poderosa "articulação letrada que rodeava o poder" (elites dirigentes, também dirá Rama) e manejava linguagens simbólicas em "direta subordinação à metrópole" ${ }^{\prime 30}$. Para oferecer uma resposta ao problema posto na introdução deste artigo, e propor simultaneamente uma leitura alternativa àquela de Ángel Rama, devemos operar alguns deslocamentos - ainda que brevemente - em relação aos três fundamentos que sustentam a tese do crítico uruguaio, quais sejam: a ideia de poder, a concepção do sistema político espanhol e o recurso à noção de intelectual para caracterizar as atividades da Companhia de Jesus.

Os dois primeiros pilares responsáveis por sustentar a "cidade" e a "fortaleza", poder e sistema político, estão intrinsecamente ligados. Se pensarmos numa metrópole (no sentido do "pacto colonial"), entendida sob a fórmula geral do Estado moderno, uniforme e centralizado, que se projeta sobre suas colônias a fim de garantir o domínio e os benefícios esperados em tal situação, torna-se plausível argumentar em favor de um poder político que deveria se realizar (e ser perceptível) por meio de um canal de comunicação que vincularia a Espanha e a América. Nesse caso, determina-se algo na metrópole, instrumentalizam-se os meios e realiza-se a ordem. Essa parece ser a moldura que informa o quadro sobre o qual trabalha Ángel Rama - que dialoga, durante o livro, com a perspectiva de "Estado" do grande historiador da Espanha moderna, José Antonio Maravall ${ }^{31}$. Havia um sistema ordenado (espanhol) que deveria ser transposto para o outro lado do Atlântico a fim de manter os habitantes socialmente dominados e subordinados ao centro de onde emanava 0 poder. Para reproduzir tal ordenamento recorreu-se às "equipes intelectuais" que foram chamadas para cumprir sua função legitimadora do poder. Lendo Rama, a

(Doutorado) - Faculdade de Filosofia, Letras e Ciências Humanas, Universidade de São Paulo, São Paulo, 2011, pp. 112-192.

${ }^{30}$ RAMA, Ángel. La ciudad letrada, p. 32.

${ }^{31}$ Cf. particularmente: MARAVALL, José Antonio. $A$ cultura do barroco: análise de uma estrutura histórica. São Paulo: Edusp, 1997; . Teoría del Estado en España del siglo XVII. Madrid:

Centro de Estudios Constitucionales, 1995. 
sensação é de que $o$ poder, em torno do qual (ou de quem?) deveria se forjar um anel protetor, vai logo ser chamado por um nome próprio (Carlos V, Felipe II), tamanha é sua personificação.

Alteremos momentaneamente o cenário. No lugar do "Estado moderno", recorramos à imagem do corpo, usual na literatura jurídica e política da Península Ibérica entre os séculos XIII e XVII, para caracterizar uma monarquia, no caso a espanhola. O corpo humano, apesar de ter uma cabeça (o rei, o príncipe, o vice-rei) que o orienta (governa), necessita dos demais órgãos e membros para existir (conselhos, cidades, universidades, cabildos, audiências, confrarias etc.). Nessa hipótese metaforizada, a lógica que presidia tal sistema político não poderia ser centralizadora nem uniformizadora e deveria supor o exercício do poder político por meio de um ato de governar partilhado invariavelmente por pessoas, corporações, territórios (pela comunidade política) - e não limitado à figura do rei ou de seu staff burocrático. Não há aí $o$ poder ou $o$ centro de poder, mas práticas políticas e poderes procedentes de corpos variados, na Espanha e na América, que se manifestam quando exercidos, golpeando nosso desejo de thes reconduzir a um único lugar e lhes imputar uma lógica de reprodução ${ }^{32}$. Se operado esse deslocamento, teríamos então uma face compósita e corporativa da monarquia, e não sua natureza absoluta.

O leitor atento já terá percebido que tal deslocamento é devedor dos pressupostos e das críticas apresentadas à aplicação invariável dos fundamentos do Estado moderno aos sistemas políticos das monarquias ibéricas dos séculos XV ao XVII - e notadamente às formulações de António Manuel Hespanha e Bartolomé Clavero ${ }^{33}$. Para o caso específico do México, fazemos coro às críticas apresentadas por Alejandro Cañeque, para quem o termo "Estado" é inadequado para definir tanto a Espanha como seus domínios americanos, sobretudo quando caracterizado como "un ente con vida propia, diferenciado tanto de gobernantes como de gobernados y capaz, por tanto, de reclamar la fidelidad de ambos grupos" ${ }^{\prime \prime 34}$. E tal termo é impróprio em suas várias faces: o "Estado Moderno" (José Antonio Maravall e Immanuel Wallerstein), o "Estado Absolutista" (Perry Anderson), o "Estado Burocrático" (Horst Pietschmann, Charles Gibson) ou o "Estado que se diluía nas instituições coloniais" (John Lynch) ${ }^{35}$. Sublinhando a dimensão corporativa, Cañeque destacou:

\footnotetext{
32 Para a noção de poder que subjaz tal afirmação, ver CLASTRES, Pierre. $A$ sociedade contra $O$ Estado. Pesquisas de antropologia política. São Paulo: Cosac \& Naify, 2012, pp. 25-66; 201-231; . Arqueologia da Violência. Pesquisas de antropologia política. São Paulo: Cosac \& Naify, 2004, pp. 135-144.

${ }^{33}$ Cf. HESPANHA, António M. Às vésperas do Leviathan. Instituições e poder político em Portugal - Século XVII. Lisboa: Almedina, 1994, introdução e capítulo 1. CLAVERO, Bartolomé. Institución politica y derecho: acerca del concepto historiografico de "Estado Moderno". Revista de Estudios Politicos, n. 19, pp. 43-57, 1981.

${ }^{34}$ CAÑEQUE, Alejandro. Cultura vicerregia y Estado colonial. Una aproximación crítica al estudio de la historia política de la Nueva España. Historia Mexicana, LI, 1, 2001, pp. 9-10.

${ }^{35}$ CAÑEQUE, Alejandro. The king's living image. The culture and politics of viceregal power in Colonial Mexico. New York: Routledge, 2004, pp. 4-6.
} 
[...] the Spanish monarchy, like all the early modern monarchies, was built on the base of a profound respect for corporate structures and for the traditional rights, privileges, and customs of different territories that made up the monarchy. [...] No one conceived of a government that did not count on the collaboration and recognition of the powers of those territories in those spheres that by right belonged to them (estate assemblies and law courts became the guardians of local and regional rights and privileges). That is, the logic of the Spanish monarchy was not one of centralization and uniformity but a loose association of all its territories, a logic very different from that of the centralizing sovereign nation-state ${ }^{36}$.

É no interior, portanto, dessa "lógica" corporativa que encontramos os jesuítas, que constituem um corpo entre outros, tanto no âmbito espanhol como no americano. A posição dos padres em tal ordenamento político sugere, por si só, um distanciamento em relação à figura do intelectual postulada na "cidade das letras" e na "fortaleza douta", na medida em que ela própria indica um "lugar de poder", sem que este esteja determinado automaticamente pelo poder do rei ou de um grupo social específico. Nesse particular, concordamos com a advertência de Óscar Mazín ao sublinhar que os intelectuais não existiram como tais nos vice-reinos da Nova Espanha e Peru, sobretudo se se considerar o sentido comum que a palavra "intelectual" tem desde o Caso Dreyfus até os dias atuais: isto é, a existência de intelectuais supõe a possibilidade de fazer a crítica do Estado-nação de maneira independente ${ }^{37}$. Acatando a proposição geral de Mazín, pode-se argumentar que seria mais correto posicionar os jesuítas numa categoria que escapasse ao anacronismo intrínseco a "intelectuais" e extrapolasse a condição de "letrados" (entendidos literalmente como magistrados e juristas). "Gente de saber": tal seria o termo mais adequado ${ }^{38}$. Parece-nos que, do ponto de vista histórico, "gente de saber", apesar de abrangente, soa menos distante às realidades sociopolíticas dos séculos XVI e XVII se

${ }^{36}$ CAÑEQUE, Alejandro. The king's living image, p. 9. Além dos referidos textos de Alejandro Cañeque, cf. LEMPÉRIÈRE, Annick. Entre Dieu et le roi, la république: Mexico, XVIe.-XIXe. siècle. Paris: Les Belles Lettres, 2004, p. 24 e ss.; HANSEN, João Adolfo. Educando príncipes no espelho. Floema, n. 2A, pp. 133-169, 2006, p. 141; ZERON, Carlos A. R. M. A construção de uma ordem colonial nas margens americanas do Império português: discussões sobre o "bem comum" na disputa de moradores e jesuítas pela administração dos índios (XVI-XVIII). 2009. Tese (Livredocência), Faculdade de Filosofia, Letras e Ciências Humanas, USP, 2009, p. 73.

37 MAZÍN, Óscar. Gente de saber en los virreinatos de Hispanoamérica (siglos XVI a XVIII). In: ALTAMIRANO, Carlos. (dir.). Historia de los intelectuales en América Latina. I. La ciudad letrada, de la conquista al modernismo. Buenos Aires: Katz Editores, 2008, p. 53. Nesta mesma página, Mazín complementa: "Recordemos que en aquellos siglos el poder político no constituía una esfera pública distinta de una sociedad formada por cuerpos. Por el contrario, se hallaba siempre disperso y la jurisdicción del rey concurría con las de otras instancias de autoridad. Por lo tanto, es impensable entender la 'posición intelectual' de aquel entonces sin una cosmovisión en la que intervenga un conjunto muy amplio de conocimientos, ideas y creencias".

${ }^{38}$ MAZÍN, Óscar. Gente de saber, p. 54. 
comparados às concepções de "intelectuais" forjadas pela sociologia da cultura no século XX, sejam elas tributárias de Max Weber, Karl Mannheim, Antonio Gramsci ou Pierre Bourdieu ${ }^{39}$. Com isso, resta claro, não negamos a importância desses autores à compreensão do problema geral da intelectualidade, especialmente nas sociedades industrializadas e capitalistas de Estados-nação do século XX, mas apontamos para a necessidade de se problematizar a aplicação de modelos sociológicos indistintamente a outros períodos.

Da cidade à república letrada ou "república do saber"40. Esse é o núcleo dos deslocamentos que gostaríamos de sugerir nas abordagens sobre o papel dos jesuítas nas sociedades coloniais. Essa "república", citando a historiadora Annick Lempérière, não seria a dos humanistas nem a de Jean Bodin, mas a escolástica de matriz aristotélica e cristã: "I'universitas, le corps politique orienté vers la recherche du bien commun, la communauté parfaite, ordonnée selon le droit et autosuffisante" ${ }^{\prime 41}$. E "letrada" ou "do saber" no sentido mais amplo relativo aos grupos que haviam completado pelo menos os estudos inferiores nos colégios do vice-reino e dominavam, portanto, o latim e o espanhol ${ }^{42}$. Essa "república letrada", então, não se organizaria para justificar o poder político da Coroa no México - mais difuso do que centralizado, conforme se sugeriu - mas para participar do governo vice-real com os demais membros da comunidade política, fosse pela formação nas letras de homens capazes de ocupar cargos na administração civil e eclesiástica, fosse pelo preparo de sujeitos aptos a integrar as diversas corporações (as ordens religiosas, os colégios, a universidade, as congregações etc.) responsáveis por partilhar o governo com o rei.

\footnotetext{
${ }^{39}$ Além de referências fundamentais para o tema, esses autores são mencionados direta ou indiretamente em CHOCANO MENA, Magdalena. La fortaleza docta, pp. 27-36.

40 "La historia de la cultura en las Indias de Castilla es impensable sin la circulación de hombres, escritos y objetos por los horizontes transoceánicos de las monarquías ibéricas. [...] El carácter práctico y docente, antes que especulativo y teórico, de los contenidos del saber, resultó imprescindible para empresa plurisecular de poblamiento, gobernación y cristianización de escala continental. Un proceso de tal envergadura demandó respuestas sintetizadoras capaces de abarcar la diversidad autóctona y de asumir la aparición de un Nuevo Mundo con un mínimo de estabilidad y permanencia. Creo que en esto último radica una de las claves de relectura de la república del saber que aquí intentamos esbozar". MAZÍN, Óscar. Gente de saber, pp. 77-78.

${ }^{41}$ LEMPÉRIÈRE, Annick. Entre Dieu et le roi, p. 66.

42 Fazemos essa distinção para especificar o modo como usamos tal expressão, dado que a noção de respublica literaria tem uma história e um debate próprios no período moderno que não equivalem completa e necessariamente àquilo que temos em mente neste artigo. Para uma aproximação a tal tema, cf. WAQUET, Françoise. Qu'est-ce que la République des Lettres? Essai de sémantique historique. Bibliothèque de l'école des chartes, t. 147, pp. 473-502, 1989. Disponível em: http://www.persee.fr/web/revues/home/prescript/article/bec 037362371989 num 147 1 450545. Acesso em: 12 mar. 2014. Para outro uso da noção de "república das letras" na América colonial, ver: ROSE, Sonia V. Hacia un estudio de las élites letradas en el Perú virreinal: el caso de la Academia Antártica. In: ALTAMIRANO, Carlos. (dir.). Historia de los intelectuales en América Latina. I. La ciudad letrada, de la conquista al modernismo. Buenos Aires: Katz Editores, 2008, pp. 79-93.
} 


\section{Sobre o autor}

Anderson Roberti dos Reis é doutor em História Social pela Universidade de São Paulo. Professor adjunto de História da América do Departamento e do Programa de Pósgraduação em História da Universidade Federal de Mato Grosso (UFMT). E-mail: dosreiss@gmail.com

Artigo recebido em 21 de abril de 2014. Aprovado em 15 de junho de 2014. 